\title{
Analysis of Penton Base Gene of Fowl Adenoviruses Reveals Recombination among Different Species of Aviadenovirus Genus
}

\author{
Vipan Kumar $^{1 *}$, Rajesh Chandra ${ }^{2}$, Rinmuanpuii Ralte ${ }^{1}$ \\ and Sarnarinder Singh Randhawa ${ }^{1}$
}

\author{
${ }^{1}$ Department of Veterinary Microbiology, Khalsa College of Veterinary and Animal \\ Sciences, Amritsar-143001, India \\ ${ }^{2}$ Department of Veterinary Microbiology, College of Veterinary and Animal Sciences, \\ G. B. Pant University of Agriculture and Technology, Pantnagar-263145, India
}

*Corresponding author

\section{Keywords}

Fowl adenovirus (FAdV), Inclusion Body Hepatitis (IBH), Hydropericardiumhepatitis syndrome (HHS), Penton base gene, Phenogram analysis

\section{Article Info}

\section{Accepted:}

10 March 2020

Available Online:

10 April 2020

\section{A B S T R A C T}

The fowl adenoviruses have been studied extensively because of their involvement in many pathogenic conditions of poultry and considerable interest to use as gene delivery vehicles. The major structural proteins of virion include hexons and pentons (penton base and fiber). Among these proteins, only hexons have been characterized extensively at molecular level. The present study was conducted for molecular characterization of penton base gene. Liver homogenates of nine fowl adenovirus 4 (FAdV 4) field isolates were propagated in chicken embryo liver cell culture and total genomic DNA was extracted. The PCR amplification revealed a 1675 bp product. Further cloning was done in pGEM-T vectors and subjected to sequencing. The nucleotide sequences were compared with other sequences of NCBI database. The sequence homology within FAdV 4 isolate sequences was $99 \%$ to $100 \%$, with FAdV10 99\%, with FAdV A $67 \%$ and FAdV D 69-70 \%. Phenogram analysis of nucleotide sequences showed close association between FAdV 4 and FAdV 10 but amino acid sequences revealed differences and recombinations were evident. Primary structural analysis revealed highly fragile nature of penton base protein. Secondary structure analysis revealed high concentration of proline residues at $\mathrm{N}$-terminal ends signifying its role in virus-host interactions and bonding with other structural proteins.

\section{Introduction}

The fowl adenoviruses have a pervasive existence among poultry flocks throughout the world (McFerran and Smyth, 2000; Fitzgerald et al. 2013). They are classified under family Adenoviridae, Genus Aviadenovirus; and divided into 5 species groups (A-E) (Marek et al., 2010; Harrach et al. 2012). A total of 11 serotypes (1-8a, 8b11) have been recognized for fowl adenoviruses (Hess, 2000).

Group -1 Fowl adenoviruses are associated with many conditions like Inclusion body hepatitis (IBH), Hepatitis-hydropericardium 
syndrome (HHS), Gizzard erosions and other minor conditions (Chandra et al., 2000; Schachner et al., 2018). While primarily affecting domestic poultry, spillover of infections have been reported in pigeons (Hess et al., 1998), buzzards (Frolich, 2005), wild black kites (Kumar et al., 2010), ducks (Ye et al., 2016), red bellied parrots (Das et al. 2017) and falcons (Mohamed et al., 2018). Transmission by horizontal and vertical routes has been well documented (Chandra et al., 2000; Grgic et al., 2006; Hafez, 2011).

The inclusion body hepatitis is a disease of 37 week old broilers. All 11 serotypes can cause the infection (Chandra et al., 2000; Mittal et al., 2014). Clinically, sudden mortality, anaemia and necrotic hepatitis (Hafez, 2011; Asthana et al., 2013) is seen. Basophillic intranuclear inclusion bodies in hepatocytes (Chandra et al., 2000; Kumar et $a l ., 2013)$ are observed. Morbidity is around $80 \%$ and mortality is variable. The hepatitishydropericardium syndrome in broilers is caused by fowl adenovirus serotype 4 (Species-C) (Kumar et al., 2011; Mase et al., 2012; Ye et al., 2016). The pathognomic finding is accumulation of clear or amber colored fluid in the pericardium. The morbidity and mortality may be very high (Chandra et al., 2000). Gross lesions, common in both conditions, are detected in liver and kidneys. There is hepatomegaly with necrotic foci, renal necrosis with enlarged kidneys and prominent tubules, spleenomegaly, hypertrophy of bursa of Fabricius and congestion of lungs. (Chandra et al., 2000; Kumar et al, 2013; Kumar et al 2011). Gizzard erosions are observed with FAdV-1 infections (Ono et al. 2004; Okuda et al., 2006).

The virion is non-enveloped isometric particle, composed of 252 capsomeres including 240 hexons and 12 pentons bases along with fibers are arranged in icosahedral symmetry. Each penton base in FAdVs except
FAdV-1 bears two fibers (Russel, 2009). Hexons and pentons are major capsid proteins which are exposed to host immune responses and play critical role in the pathogenesis of virus. The serotype specific residues are present on hexons where as highly conserved group specific residues are present on Penton base. A number of epidemiological and phylogenetic studies have been done involving hexon protein of Fowl adenovirus (Meulemans et al., 2004; Asthana et al., 2013, Chen et al., 2019) because it is most structurally exposed protein. However corresponding studies involving Penton base are lacking. Penton base of human adenoviruses is involved in attachment to integrin receptors on host cells (Wickham et al., 1993) and internalization of virion (Russel, 2009). Therefore, this study was undertaken to characterize the penton base gene.

\section{Materials and Methods}

A total of nine virus isolates (Table 1) of Fowl Adenovirus serotype (FAdV) 4, collected from out breaks of Inclusion body hepatitis and Hydropericardium-hepatitis syndrome were used in this study. The liver homogenates $(10 \% \mathrm{w} / \mathrm{v})$ of all isolates were maintained in the Department of Veterinary Microbiology, College of Veterinary and Animal Sciences, Pantnagar. All virus isolates, were revived on Chicken Embryo Liver Cell (CEL) culture using standard procedure. Total genomic DNA was extracted from the infected cell cultures at $6^{\text {th }}$ passage level for each isolate showing 70-80\% CPE Qiagen DNA easy blood and tissue kit as per manufacturer's instructions. Genomic DNA from un-infected cell culture was also extracted for control studies. Quality and purity of DNA were checked by submerged agarose gel electrophoresis using $0.8 \%$ agarose in $0.5 \mathrm{X}$ TBE (pH 8.0) buffer (Sambrook et al., 1989). 


\section{Cloning of penton base gene}

For amplification of penton base gene, primers were designed from FAV10 penton gene (Accession no. M87008) (Sheppard and Trist, 1992) using GeneTool software.

PFC9 (Forward): 5' CGC TTT TAC TTA CGA GAG CTA GAT ACC 3'

PRA10 (Reverse): 5' TGG ACA TGT TCA GTC CTA CTG CAA 3'.

The amplification was carried out in $50 \mu \mathrm{l}$ reaction mixture containing $30 \mathrm{ng}$ of genomic DNA, 100 picomoles of each primer, $10 \mathrm{mM}$ DNTPs each and 1 Unit of Taq polymerase ( Fermantas, Germany). The amplification conditions used were standardized at; initial denaturation $94^{\circ} \mathrm{C}$ for 4 minutes followed by 35 cycles of denaturation (at $94^{\circ} \mathrm{C}$ for 1 minute), annealing (at $55^{\circ} \mathrm{C}$ for 1 minute) and extension (at $68^{\circ} \mathrm{C}$ for 1.5 minutes).

Negative control of PCR reactions were run to detect non-specific amplification of chicken genomic DNA. The amplicons were analyzed on $1.5 \%$ Agarose gel and size was determined by comparing with standard molecular size marker. Further purification was carried out by using QIAquick Gel Extraction Kit, (Qiagen, Germany).

All purified PCR products were cloned in pGEM®-T Easy vector as per the manufacturer's instructions. The ligated plasmids with Penton base genes were further used to transform DHFa E.Coli cells using Calcium Chloride protocol (Sambrook et al., 1989).

The transformed $E$. coli bacteria were grown on Luria Bertani agar plates containing Ampicillin $(50 \mu \mathrm{l} / \mathrm{ml}$, IPTG $(100 \mathrm{~mm})$ and Xgal $(50 \mathrm{mg} / \mathrm{ml})$. The positive clones were selected on the basis of blue -white colony selection and antibiotics resistance. Further confirmation of positive clones was done using colony PCR. The recombinant plasmids were isolated from bacteria by alkaline lysis method (Sambrook et al., 1989). The recombinant clones were subjected to double strand DNA sequencing at the DNA sequencing facility of University of Delhi, South Campus, New Delhi. All sequences were submitted to NCBI gene bank and accession numbers were obtained.

\section{Sequence and phenogram analysis}

The open reading frame of all sequences was identified by using GENE TOOL software. The sequences were analyzed using NCBI online BLAST server to identify the sequence specificity. The amino acid sequences were deduced by using 'EditSeq' programme of Lasergene (DNASTAR Inc, USA) software. Both nucleotide and amino acid sequences were aligned separately by using Clustal $\mathrm{W}$ method of 'MegAlign' programme. Sequences of some reference strains (Table 2), retrieved from NCBI database, were also included in this study.

\section{Structural analysis of penton base protein}

Primary and secondary structure analysis of penton protein of all the nine isolates was done based on deduced amino acid sequence by using online servers, ProtParam (http://www.expasy.org/tool/) and Swissmodel workspace respectively.

\section{Results and Discussion}

All FAdV 4 isolates were propagated in primary chicken embryo liver cell culture. The cytopathic effects (CPE) were characterized by rounding and detachment of cells, change in refractive index, similar to those reported by earlier workers (Asthana $e t$ al., 2013, Kumar et al., 2013).Genomic DNA was isolated from the infected cell cultures at 
$6^{\text {th }}$ passage level for each isolate showing 70 $80 \%$ CPE.

\section{Cloning of penton base gene}

The primers for PCR amplification were designed using the penton base sequence of FAV-10 which has an open reading frame (ORF) of 1575 bp (Sheppard and Trist, 1992) and has been found to be closely related to FAV-4 in earlier studies based on Hexon gene sequences (Davison et al., 2003). The amplification of Penton base gene of all isolates resulted in a single product of 1675 bp size (Fig. 1). The nucleotide sequences, obtained after sequencing, were submitted to GeneBank and accession numbers; EU925581, EU925580, EU925579, EU925578, EU925577, EU925576, EU925575, EU925574 and EU925573 were obtained.

\section{Sequence and phenogram analysis}

Knowledge of DNA sequences has become indispensable for basic biological research, diagnostics, biotechnology, forensic biology and biological evolutionary studies. The advent of DNA sequencing has significantly accelerated biological research and discovery. The DNA sequences of all isolates revealed an ORF of $1578 \mathrm{bp}$. The ORF of FAdV 10, FAdV 9, FAdV 1 and Egg drop syndrome (EDS) virus has been reported to be $1575 \mathrm{bp}$ (Sheppard and Trist, 1992), 1713 bp (Ojkic et al., 2002), 1548 bp (Chiocca et al., 1996 and Akopian et al., 1996) and1359 bp (Rohn et al., 1997) in length, respectively.

The $\mathrm{G}+\mathrm{C}$ contents of all sequences were found to be between $59.90 \%$ to $59.95 \%$ which is similar to FAV 10 but significantly greater than those of FAV 1 (55.0\%) (Akopian et al., 1996), Haemorrhagic enteritis virus (HEV) (33.8 \%) and EDS (41\%) (Jucker et al., 1996) penton base sequences. Percentage wise identity analysis between different isolates used in this study revealed $99-100 \%$ identity between them. With FAV A identity was $67 \%$. Sequence similarity with Duck adenovirus 1 and haemorrhagic enteritis virus was $39 \%$.

A rooted phenogram (Fig. 2) of nucleotide sequences showed that the adenoviruses clustered into three groups. One group was formed by viruses affecting avian species, second group was formed by mammalian adenoviruses and third group was formed by murine adenovirus 1 only.

Avian adenoviruses further grouped into two clusters. In one cluster FAdV 4 isolates were closely grouped which in turn were closely related to FAdV 10. Both FAdV 4 and FAdV 10 serotypes showed close relation with FAV A than FAV D. Northern Aplomado Falcon adenovirus further diverged from this group. Second cluster of avian adenoviruses was formed by Duck adenovirus 1 closely related to Possum adenovirus 1 and Haemorrhagic enteritis virus of turkey closely related to Raptor adenovirus 1.

However, phenogram of amino acids (Fig. 3) revealed somewhat different relationships among FAdV 4 penton bases itself which may be due to recombination events. Both FAdV 4 and FAdV 10 isolates were more closely related to FAdV 9 and then to FAdV 1.

\section{Structural analysis of penton base protein}

The polypeptide of Penton base was found to be 525 amino acids long. The primary structure analysis of protein revealed highly conserved nature of penton base sequences among different serotypes affecting different hosts (Fig. 4). The amino acid sequences of FAdV 4 and FAdV 10 revealed significant similarity. 
A region of 47 amino acids corresponding to $\mathrm{N}$ terminal end of FAV 4 was absent in Duck adenovirus 1, Raptor adenovirus 1 and Haemmorhagic enteritis virus of turkeys explaining smaller penton base protein in genera Atadenovirus and Siadenovirus. FAdV 9 features a sequence of 40 amino acids (from $8^{\text {th }}$ amino acid to $47^{\text {th }}$ amino acid) among $\mathrm{N}$ terminal amino acids, which is absent in all other adenoviral sequences making it the longest penton base sequence known so far.
Human Adenoviruses had unique sequences in the middle of polypeptide. The penton base polypeptide had estimated half-life of $30 \mathrm{hrs}$ in mammalian reticulocytes, $>20 \mathrm{hrs}$. in yeast cells and $>10 \mathrm{hrs}$ in E.coli. The instability index was found to be between 44 and 48 suggesting that the protein may be unstable outside cell, as proteins having instability index value below 40 are considered to be stable (Gasteiger et al., 2005).

Table.1 Epidemiological details of field isolates

\begin{tabular}{|l|l|l|c|c|l|}
\hline SI. No. & Isolate & Condition(s) & Flock Size & \% Mortality & Age and Type of Birds \\
\hline 1. & HPS-G & HHS & $\mathbf{4 0 0 0 0}$ & 50 & Broilers (5 weeks) \\
\hline 2. & HPS-R & HHS & $\mathbf{3 0 0 0}$ & 66 & Broilers (5 weeks) \\
\hline 3. & HPS-K & HHS & $\mathbf{2 0 0 0}$ & 60 & Broiler (1 week) \\
\hline $\mathbf{4 .}$ & PB-04 & IBH & $\mathbf{2 2 0 0}$ & 9.8 & Broiler (6-8 wks) \\
\hline $\mathbf{5 .}$ & PB-05 & IBH & $\mathbf{2 0 0 0}$ & 10 & Broiler (4-6 wks) \\
\hline 6. & PJ-06 & IBH & $\mathbf{1 0 0 0}$ & 60 & Broiler (4-5 wks) \\
\hline 7. & PK-01 & HHS & $\mathbf{4 0 0 0}$ & 2.8 & Broiler (6-8 wks) \\
\hline 8. & PP-01 & HHS & $\mathbf{5 0 0}$ & $\mathbf{1 0}$ & Broiler (4-6 wks) \\
\hline 9. & PR-06 & IBH & N.A. & $\mathbf{5 0 *}$ & Kite (N.A) \\
\hline
\end{tabular}

Table.2 Details of sequences downloaded from NCBI used in this study

\begin{tabular}{|l|l|}
\hline Sequence & Accession no. \\
\hline Fowl adenovirus D (FAV 9) & NC_000899 \\
\hline Fowl adenovirus A (FAV 1) & NC_001720 \\
\hline Fowl adenovirus 10 & M87008 \\
\hline Human adenovirus 22 & FJ404771 \\
\hline Human adenovirus 11 & AF532578 \\
\hline Murine adenovirus 1 & MAU95843 \\
\hline Raptor adenovirus 1 & EU715130 \\
\hline Canine adenovirus 1 & CAU77082 \\
\hline Human adenovirus E & NC_003266 \\
\hline Northern aplomado phalcon adenovirus & AY683541 \\
\hline Possum adenovirus 1 & AF249332 \\
\hline Bovine adenovirus 2 & BAU44123 \\
\hline Porcine adenovirus 3 & AF083132 \\
\hline Turkey adenovirus & AF074946 \\
\hline Duck adenovirus 1 & X99782 \\
\hline
\end{tabular}




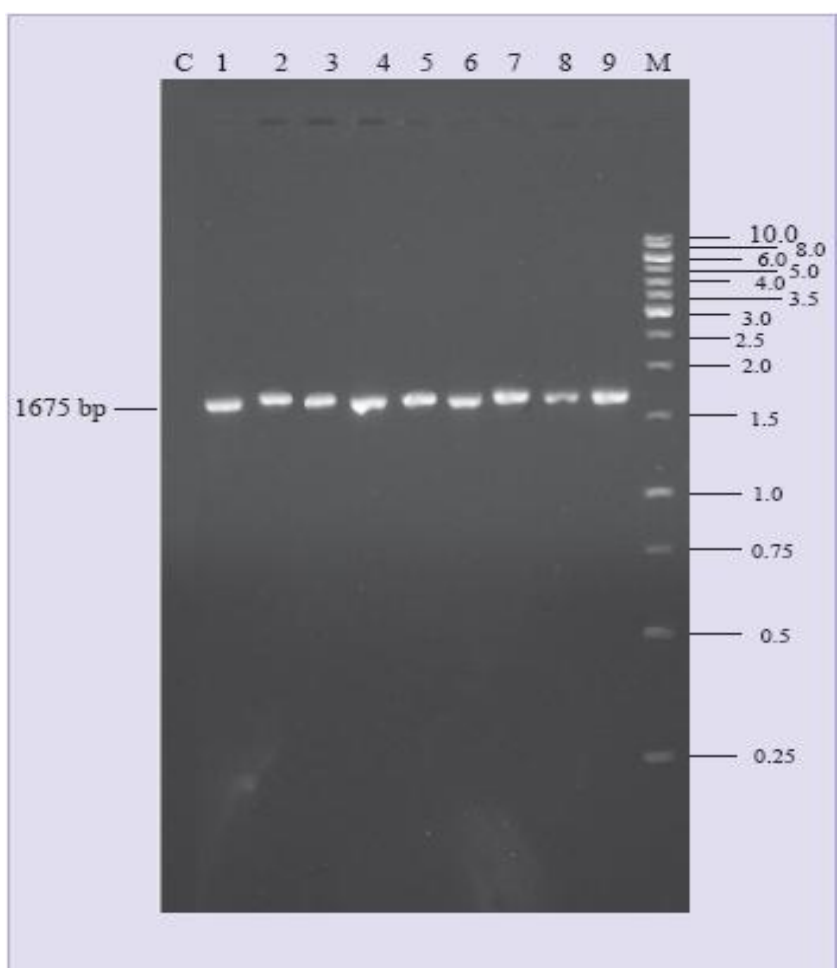

Fig.1 Amplification of Penton base gene . Lane 1. C-negative control, lane 2. PJ-06, lane 3. PB-05, lane 4. PB-04, lane 5. PP-01, lane 6. PR-06, lane 7. PK-01, lane 8. HPS-K, lane 9. HPS-R, lane 10 HPS-G, lane M. 10-kb mol. size marker

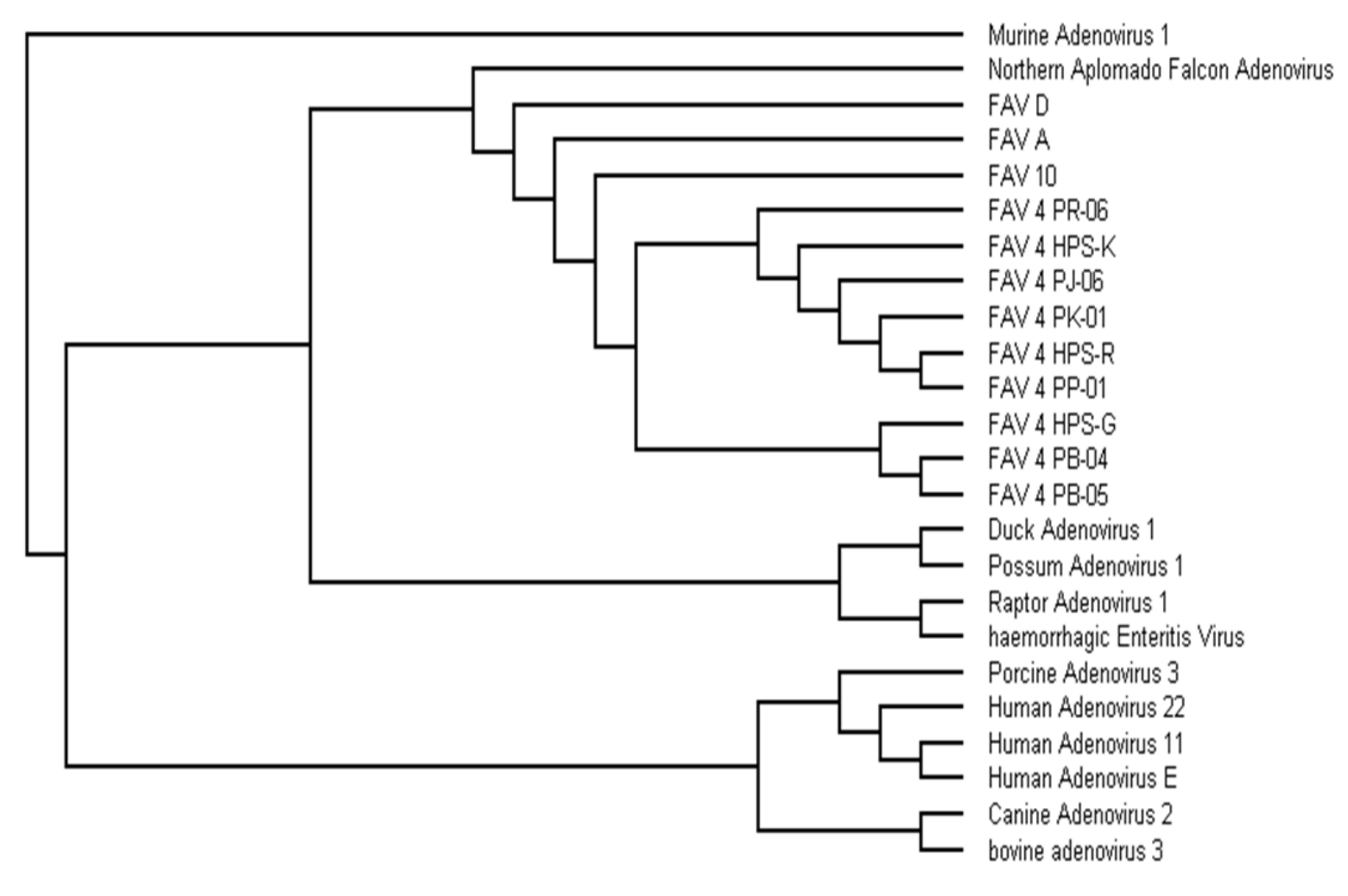

Fig.2 Phenogram of nucleotide sequences of Penton base 


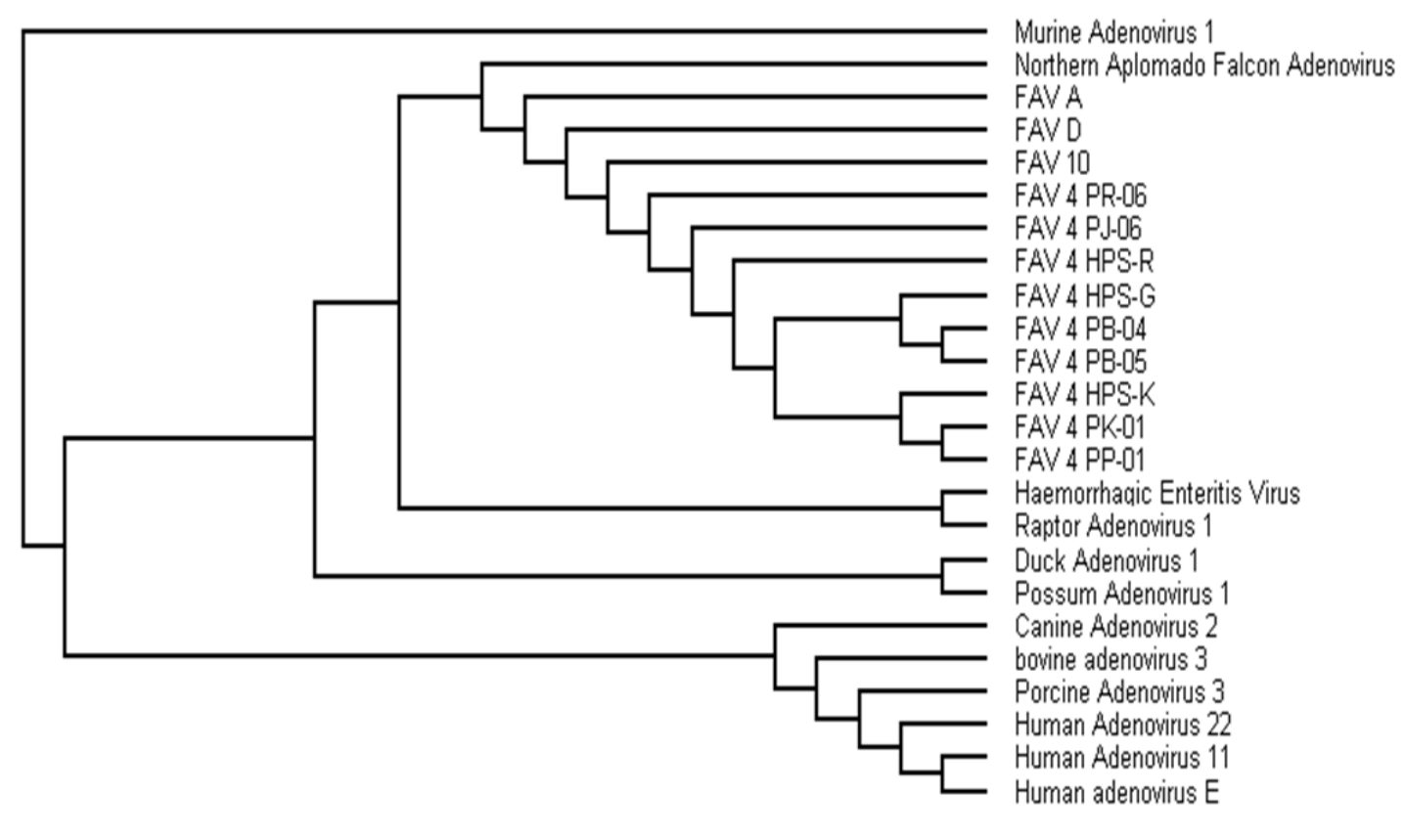

Fig.3 Phenogram of Amino acid sequences of Penton base

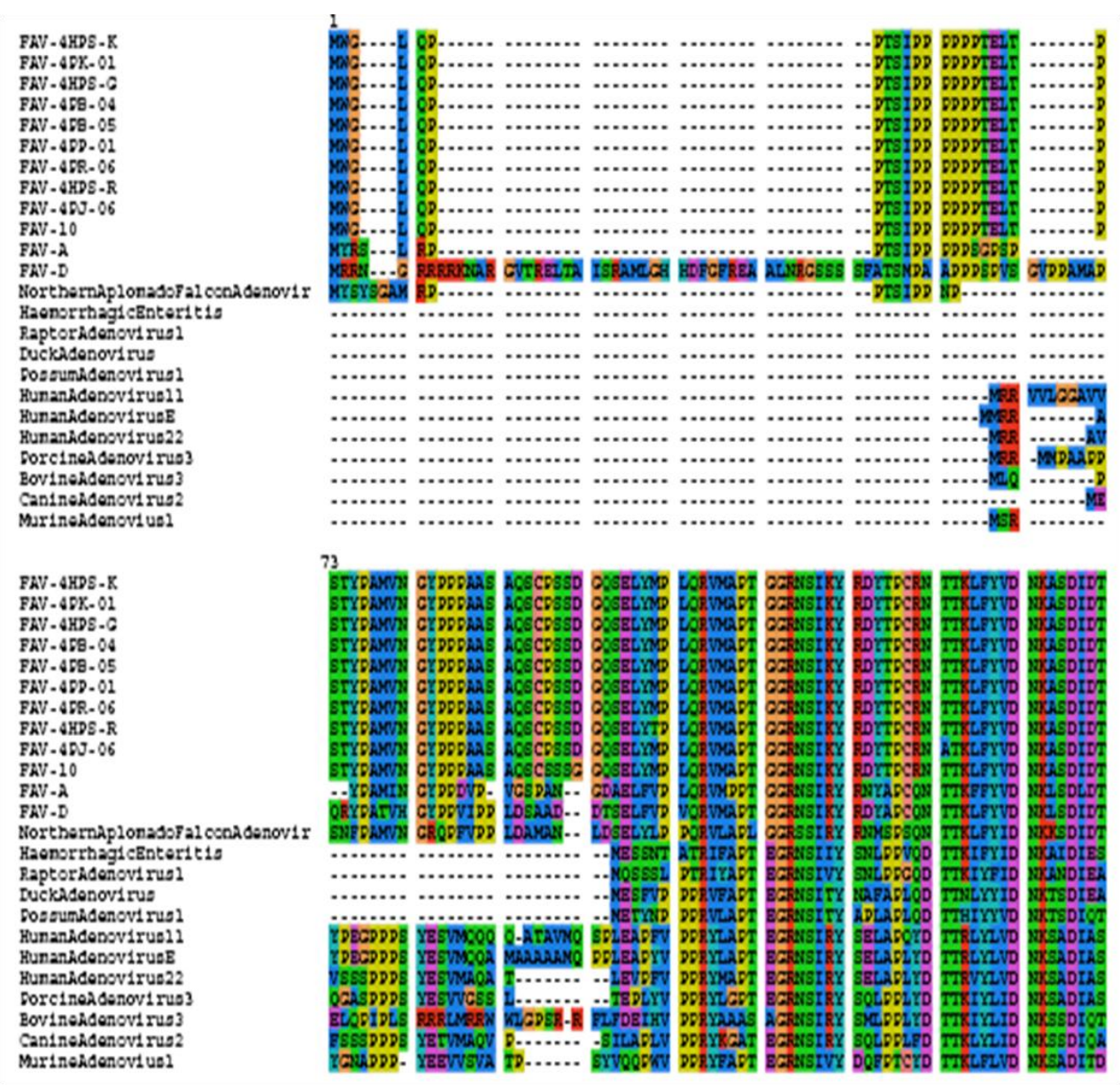

Fig.4 Alignment of peptides of penton base: N- terminal ends 
Penton base in Human adenovirus has been reported to be unstable and it is susceptible to changes of $\mathrm{pH}$, ionic strength and action of trypsin enzyme (Rexroad et al., 2006).

Secondary structure analysis revealed high concentration of proline residues (29\% of total proline) at $\mathrm{N}$-terminal ends. The high concentration of proline provides frequent bends in structure but it also provides rigidity to $\mathrm{N}$ terminal ends. This suggests that $\mathrm{N}$ terminal end of penton base may be involved in various interactions including that with cellular receptors. The X-ray crystallographic structure of an enveloped bacteriophage PRD1 (Abrescia et al., 2004), which is close relative of adenoviruses and has structural similarities, revealed that N-terminal 13 residues of the protein $\mathrm{P} 31$, equivalent to the penton base, interacts with peripentonal P3 proteins (equivalent to hexon protein).

Our studies provide evidence that recombination events have occurred in penton base gene sequence during the course of evolution of Fowl adenoviruses.

\section{Acknowledgement}

The facilities provided by the Dean, College of Veterinary and Animal Sciences, G B Pant University of Agriculture and Technology are duly acknowledged.

\section{References}

Abrescia N.G, Cockburn J.J., Grimes J.M., Sutton G.C., Diprose, J.M, Butcher, S.J., Fuller, S.D., San Martín, C., Burnett, R. M., Stuart, D.I., Bamford, D.H. and Bamford, J.K. (2004). Insights into assembly from structural analysis of bacteriophage PRD1. Nature. 4; 432 (7013): 68-74.

Akopian, T.A., Lazareva, S.E., Tikhomirov, E., Karpov, V.A., and Naroditsky, B.S.
(1996). Genes for fowl adenovirus CELO penton base and core polypeptides. Archives of Virology, 141, 357-365.

Asthana, M., Chandra, R., and Kumar, R. 2013. Hydropericardium syndrome: current state and future developments. Archives of virology, 158(5), 921-931.

Chandra, R., Shukla S.K. and Kumar M. (2000). The Hydropericardium Syndrome and Inclusion Body Hepatitis in Domestic Fowl. Trop. Animal Health Prod. 32, (2) 99-111.

Chen, L., Yin, L., Zhou, Q., Peng, P., Du, Y., Liu, L., Zhang, Y., Xue, C., and Cao, Y. (2019). Epidemiological investigation of fowl adenovirus infections in poultry in China during 2015-2018. BMC veterinary research, 15(1), 271.

Chiocca, S., Kurzbauer, R., Schaffner, G., Baker, A., Mautner, V. and Cotton, M. (1996). The complete DNA sequence and genomic organization of the avian adenovirus CELO. J. Virol. 70: 29392949.

Das, S., Fearnside, K., Sarker, S., Forwood, J.K. and Raidal, S.R. (2017). A novel pathogenic aviadenovirus from redbellied parrots (Poicephalus rufiventris) unveils deep recombination events among avian host lineages. Virology. 502:188-197.

Davison, A.J., Banko, M. and Harrach, B. (2003). Genetic content and evolution of adenoviruses. J. Gen. Virol. 84: 2895-2908.

Fitzgerald, SD (2013). Adenovirus infections (Introduction) In: Swayne, DE, Glisson, JR, McDougald, LR, Nolan, LK, Suarez, D, editors. Diseases of poultry. 13th Edn. Ames, Iowa, USA: John Wiley and Sons. pp. 289-290.

Frolich, K., Prusas, C., Schetller, E. and Hafez, H. M. (2005). Antibodies to adenoviruses in free living common buzzards from Germany. Journal of 
Wildlife Diseases. 38: 633-636.

Gasteiger, E., Hoogland, C., Gattiker, A., Duvaud, S., Wilkins, M.R., Appel, R.D. and Bairoch, A. (2005). Protein identification and analysis tools on the ExPaSy server. In: (Ed.) John M. Walker: The proteomics protocols handbook, Humana Press. Pp 571-607.

Grgic, H., Philippe, C., Ojkic, D. and Nagy, E. (2006). Study of vertical transmission of fowl adenoviruses. Canadian J. Vet. Res. 70:230-233.

Hafez, H.M. (2011). Avian adenoviruses infections with special attention to inclusion body hepatitis/ hydropericardium syndrome and egg drop syndrome. Pakistan Veterinary Journal 31(2):85-92.

Harrach, B., M. Benkö, G.W. Both, M. Brown, A.J. Davison, M. Echavarria, M. Hess, M.S. Jones, A. Kajon, H.D. Lehmkuhl, V. Mautner, S.K. Mittal and G. Wadell (2012). Family Adenoviridae. In: Virus Taxonomy: Ninth Report of the International Committtee on Taxonomy of Viruses, 9th ed. A.M.Q. King, M.J. Adams, E.B. Carstens, E.J. Lefkowitz (Eds), Elsevier Academic Press, New York. pp. 125141.

Hess, M. (2000) Detection and differentiation of avian adenoviruses: A review, Avian Pathology, 29:3, 195-206.

Hess, M., Prusas, C., Vereecken, M., De Herdt, P., (1998). Isolation of fowl adenoviruses serotype 4 from pigeons with hepatic necrosis. Berl. Munch. Tierarztl. Wochenschr. 111, 140-142.

Jucker, M.T., McQuiston, J.R., van den Hurk, J.V., Boyle, S.M. and Pierson, F.W. (1996). Characterization of the haemorrhagic enteritis virus genome and the sequence of the putative penton base and core protein gene. J. Gen. Virol. 77: 469-479.

Kumar, R. and Kumar, V (2011).
Pathogenecity of Fowl Adenoviruses in Day-Old Chicks. Indian Vet. J. 88(12):43-45.

Kumar, R., Kumar, V., Asthana, M., Shukla, S.K. and Chandra, R. (2010). Isolation and Identification of a Fowl Adenovirus from Wild Black Kites (Milvus migrans). Journal of Wildlife Diseases, 46(1), 2010, pp. 272-276.

Kumar, V., Kumar, R., Chandra, R., Bhatt, P., and Dhama, K. (2013). Outbreaks of inclusion body hepatitis (IBH) in chickens: pathological studies and isolation of fowl adenovirus. Advances in Animal and Veterinary Sciences, 1(3S), 21-24.

Marek A, Günes A, Schulz E, Hess M (2010). Classification of fowl adenoviruses by use of phylogenetic analysis and highresolution melting-curve analysis of the hexon L1 gene region. Journal of Virological Methods. 170 (1-2):147154.

Mase, M., Nakamura, K. and Minami, F., (2012). Fowl Adenoviruses Isolated from Chickens with Inclusion Body Hepatitis in Japan, 2009-2010. Journal of Veterinary Medical Science. 74(8):1087-1089.

McFerran, J. B., and Smyth, J. A. (2000). Avian adenoviruses. Revue Scientifiqueet Technique-Office International des Epizooties, 19(2), 589-598.

Meulemans, G., Couvreur, B., Decaesstecker, M., Boschmans, M. and Berg, T. P. van Den (2004). Phylogenetic analysis of fowl adenoviruses. Avian Pathology. 33(2): 164-170.

Mittal, D., Jindal, N., Tiwari, A. K. and Khokhar, R. S. (2014). Characterization of fowl adenoviruses associated with hydropericardium syndrome and inclusion body hepatitis in broiler chickens. Virus disease, 25(1), 114119. 
Mohamed, M. H. A., El-Sabagh, I M, Ahmed, A M. A. M., Al-Ali, Alramadan, M,. Lebdah, M A, Ibrahim, A M, AbdulRahman S. Al-Ankari (2018). Molecular characterization of fowl aviadenoviruses species $\mathrm{D}$ and $\mathrm{E}$ associated with inclusion body hepatitis in chickens and falcons indicates possible cross-species transmission, Avian Pathology, 47:4, 384-390.

Ojkic, D. and Nagy, E. (2000). The complete nucleotide sequence of fowl adenovirus type 8. J. Gen. Virol.81: 1833-1837.

Okuda, Y., Ono, M., Shibata, I., Sato, S. and Akashi, H. (2006). Comparison of the polymerase chain reaction- restriction length polymorphism pattern of fiber gene and pathogenecity of serotype-1 fowl adenovirus isolates from gizzard erosions and from feces of clinically healthy chickens in Japan. $J$ Vet. Diag. Invest. 18 : 162-167.

Ono, M., Okuda, Y. and Shibata, I. (2004). Pathogenecity by parenteral injection of fowl adenovirus isolated from gizzard erosions and resistance to reinfection in adenoviral gizzard erosions in chickens. Vet. Pathol. 41: 483-489.

Rexroad, J., Evans, R. K. and Middaugh, C. R. (2006). Effect of $\mathrm{pH}$ and ionic strength on the physical stability of adenovirus type 5. J. Pharm. Sci. 95: 237-247.

Rohn, K., Prusas, C., Monreal, G. and Hess,
M. (1997). Identification and characterization of penton base and pVIII protein of egg drop syndrome virus. Virus res. 47: 59-65.

Russel, W.C. (2009). Adenoviruses: update on structure and function. J. Gen. Virol. 90: 1-20.

Sambrook, J., Fritsch, E.F. and Maniatis, T. (1989). Molecular Cloning. A Laboratory Manual 198(9) edition $2^{\text {nd }}$. Cold Spring Harbour Laboratory Press Cold Spring Harbour NY.

Schachner, A., Matos, M., Grafl, B., and Hess, M. (2018). Fowl adenovirusinduced diseases and strategies for their control-a review on the current global situation. Avian Pathology, 47(2), 111126.

Sheppard, M. and Trist, H. (1992). Characterization of the avian adenovirus penton base. Virology. 188: 881-886.

Wickham, T. J., P. Mathias, D. A. Cheresh, and G. R. Nemerow. (1993). Integrins alpha $\mathrm{v}$ beta 3 and alpha $\mathrm{v}$ beta 5 promote adenovirus internalization but not virus attachment. Cell 73:309-319.

Ye, J., Liang, G., Zhang, J., Wang, W., Song, N., Wang, P., Zheng, W., Xie,Q, Shao, H, Wan, Z., Wang, C., Chen, H., Gao, W. and Qin, A. (2016). Outbreaks of serotype 4 fowl adenovirus with novel genotype, China. Emerging Microbes and Infections, 5(1), 1-12.

\section{How to cite this article:}

Vipan Kumar, Rajesh Chandra, Rinmuanpuii Ralte and Sarnarinder Singh Randhawa. 2020. Analysis of Penton Base Gene of Fowl Adenoviruses Reveals Recombination Among Different Species of Aviadenovirus Genus. Int.J.Curr.Microbiol.App.Sci. 9(04): 1045-1054. doi: https://doi.org/10.20546/ijcmas.2020.904.124 